\title{
Spillovers Espaciais no desenvolvimento educacional dos municípios da Amazônia Clássica Brasileira'
}

\author{
Mário Sérgio Pedroza Lobão \\ Instituto Federal do Acre \\ Rubicleis Gomes da Silva \\ Universidade Federal do Acre
}

\section{Resumo}

As políticas públicas educacionais aplicadas na Amazônia Clássica brasileira permitiram mudanças nas cidades da região de forma geral. Com isso, esse trabalho buscou verificar a existência de spillovers educacionais ${ }^{2}$ nos municípios da Amazônia Clássica do Brasil. Traçou como objetivos: identificar padrões espaciais de desenvolvimento educacional entre os municípios; b) detectar a existência de relacionamento espacial entre variáveis socioeconômicas e o crescimento do nível educacional e; c) evidenciar os efeitos diretos e indiretos de variáveis socioeconômicas sobre o crescimento do nível educacional dos municípios do norte brasileiro. Para isso, foi utilizada a metodologia de análise exploratória de dados espaciais e estimação de modelos espaciais, por meio da qual verificou-se que a taxa de pobreza, a taxa de analfabetismo e a taxa de trabalho infantil dos municípios impactam diretamente, mas de forma negativa no desenvolvimento das próprias cidades. Esses efeitos também transbordam para cidades vizinhas, confirmando a presença de spillovers educacionais e a necessidade de se pensar em políticas públicas educacionais de forma regionalizada visando à diminuição da pobreza, do trabalho infantil e a promoção da educação aos analfabetos.

Palavras-chave: Desenvolvimento educacional. Transbordamentos espaciais. Amazônia Clássica do Brasil.

\section{Spillovers Space in educational development of the municipalities of the Brazilian Classical Amazon}

\footnotetext{
Abstract

The educational public policies applied in the Brazilian Classical Amazon allowed changes in the cities of the region in general. Thus, this study aimed to verify the existence of educational spillovers in the municipalities of the
}

1 Entenda-se a Amazônia Clássica brasileira como a extensão que compreende a Região Norte do Brasil na sua totalidade, integrando os estados do Acre, Amazonas, Amapá, Pará, Rondônia, Roraima e Tocantins.

2 Spillovers educacionais representam os transbordamentos que ocorrem entre municípios vizinhos, ou seja, busca-se analisar se o padrão de desenvolvimento educacional de uma localidade tem ligação/influência no desenvolvimento da educação de seu município vizinho, seja de forma positiva ou negativa. 
Brazilian Classical Amazon. Traced aims at identifying spatial patterns of educational development among municipalities; b) detecting the existence of spatial relationship between socioeconomic variables and the growth of educational level and; c) show the direct and indirect effects of socioeconomic variables on the growth of the educational level of the municipalities of northern Brazil. For this, it was used the methodology of exploratory analysis of spatial data and estimation of spatial models, where the poverty rate, illiteracy rate and child labor rates of municipalities have a direct impact, but in a negative way in the development the cities themselves, as well as those overflow effects to neighboring cities, confirming the presence of educational spillovers and the need to think of public educational policies by region, aiming to reduce poverty, child labor and the promotion of education to the illiterate.

Keywords: Educational development. Spatial spillovers. Brazilian Classical Amazon.

\section{Spillovers Espaciales en el desarrollo educacional de los municipios de la Amazonia Clásica Brasileña}

\section{Resumen}

Las políticas públicas educativas aplicadas en la Amazonia Clásica brasileña permitieron cambios en las ciudades de la región de forma general. Con ello, ese trabajo buscó verificar la existencia de spillovers educacionales en los municipios de la Amazonia Clásica brasileña. Trazó como objetivos: a) identificar patrones espaciales de desarrollo educativo entre los municipios; b) detectar la existencia de una relación espacial entre variables socioeconómicas y el crecimiento del nivel educativo; c) evidenciar los efectos directos e indirectos de variables socioeconómicas sobre el crecimiento del nivel educativo de los municipios del norte brasileño. Para ello, se utilizó la metodología de análisis exploratorio de datos espaciales y estimación de modelos espaciales, donde se verificó que la tasa de pobreza, la tasa de analfabetismo y la tasa de trabajo infantil de los municipios impactan directamente, pero de forma negativa en el desarrollo de las propias ciudades, como también esos efectos desbordan hacia ciudades vecinas, confirmando la presencia de spillovers educacionales y la necesidad de pensar en políticas públicas educativas de forma regionalizada, con miras a la disminución de la pobreza, del trabajo infantil y la promoción de la educación a los analfabetos.

Palabras clave: Desarrollo educativo. Desbordamientos espaciales. Amazonia Clásica brasileña.

\section{INTRODUÇÃO}

Nos últimos anos, a educação tem apresentado resultados cada vez mais positivos no cenário nacional. As pessoas passaram a ter uma maior acessibilidade ao ensino e com uma melhor qualidade em todos os níveis e modalidades educacionais, influenciando diretamente no aumento de renda das famílias brasileiras. É notório que esses resultados são frutos de várias políticas públicas implantadas e executadas na educação pública brasileira.

Não obstante, é perceptível que a aplicação dos investimentos na área está se refletindo e gerando pontos positivos em todos os estados brasileiros. Como prova disso, tem-se o Programa Internacional de Avaliação dos Estudantes - PISA (na sigla em inglês), que, conforme o Ministério da Educação e Cultura - MEC, em 2012, o Brasil foi o país que mais cresceu na área de matemática nos últimos anos. 
O Índice de Desenvolvimento Humano - IDH, por meio da sua dimensão educacional (IDHE), tem mostrado essa evolução nos níveis do Brasil, conforme aponta o último levantamento do Programa das Nações Unidas para o Desenvolvimento - PNUD, ao mostrar que, em 2000, o IDHE apresentava o valor de 0,456, passando para 0,637 em 2010, uma variação de 0,181. Outro sinalizador desse processo de expansão da melhoria educacional no Brasil é o Índice de Desenvolvimento da Educação Básica - IDEB, índice criado pelo MEC para medir o avanço da educação Básica no País, que saiu de 5,0 em 2011 para 5,2 em 2013, nos anos iniciais do ensino fundamental.

Apesar desses apontamentos positivos, verifica-se que, no Brasil, pode-se dizer, após a observação dos dados regionais, que a distribuição regional da educação brasileira apresenta-se de forma desigual. É observado que as regiões Sul, Sudeste e Centro-Oeste do Brasil concentram os melhores resultados educacionais, conforme aponta o IDH-E de 2010, onde estas regiões apresentaram resultados 0,669, 0,671 e 0,663, respectivamente. Já as regiões Norte e Nordeste são aquelas que demonstram resultados mais tímidos, com valores de 0,586 e 0,565.

Nesse mesmo sentido, observa-se que a distribuição de renda das regiões do Brasil apresenta-se de forma semelhante à distribuição educacional, pois é visível que as regiões Norte e Nordeste são aquelas com maiores índices de concentração de renda, sendo de 0,613 e 0,615, respectivamente. Sabe-se ainda que a educação tem impactos diretos no crescimento econômico, indicando que a distribuição do nível de desenvolvimento educacional está diretamente relacionada com a distribuição do crescimento econômico dos municípios.

A Amazônia Clássica brasileira, tida como a região Norte do Brasil, é composta pelos estados do Acre, Amazonas, Amapá, Pará, Rondônia, Roraima e Tocantins, é emblemática nesse contexto, pois é uma das regiões brasileiras que menos apresenta saldo positivo no desenvolvimento educacional. Outro fato característico são as influências que cada município exerce em seu entorno, pois alguns mais desenvolvidos, como é o caso das próprias capitais dos estados, sinalizam parâmetros a serem seguidos por municípios vizinhos.

Diante do exposto, esta pesquisa partiu do seguinte questionamento: ocorrem efeitos de spillovers educacionais nos municípios da Região Norte em decorrência do crescimento econômico? Pois, nota-se que a educação em alguns espaços geográficos possuem influências que vão além das fronteiras onde se realiza, de maneira a influenciar regiões vizinhas. Assim, direciona-se este trabalho com a hipótese de que não existem spillovers educacionais entre os municípios da região Norte do Brasil, haja vista que cada município possui características peculiares que o individualizam dos demais, ainda mais se tratando de uma região tão heterogênea nos aspectos sociais e econômicos.

A pesquisa assume como objetivo geral: verificar a existência de spillovers educacionais nos municípios da Região Norte, mais especificamente: a) identificar padrões espaciais de desenvolvimento educacional entre os municípios; b) detectar a existência de relacionamento espacial entre variáveis socioeconômicas e o crescimento do nível educacional e; c) evidenciar os efeitos diretos e indiretos de variáveis socioeconômicas sobre o crescimento do nível educacional dos municípios do norte brasileiro. 
Dessa forma, o presente trabalho mostra-se relevante uma vez que visa traçar a distribuição espacial do desenvolvimento educacional dos municípios da região Norte do Brasil e os impactos que essa distribuição proporciona no crescimento econômico do entorno dessas cidades. Na literatura existente, poucos são os trabalhos que abordam a temática, principalmente para a região de estudo. Outro fato é que, a partir dos resultados obtidos, torna-se possível verificar se as diferenças educacionais dos municípios da região podem explicar o grau de concentração do crescimento econômico da localidade.

\section{EDUCAÇÃO E CRESCIMENTO ECONÔMICO}

Antes de mais nada, faz-se necessário entender que existem dois pontos de vista clássicos sobre desenvolvimento. Para Furtado (1980), o primeiro associa igualmente o desenvolvimento com o crescimento, em que se refere única e exclusivamente à evolução do sistema social de produção, de maneira que o crescimento se dá pela acumulação e com o progresso de técnicas, favorecendo a elevação da produtividade. O segundo, mais complexo, decorre do grau de atendimento e satisfação das necessidades e bem-estar do ser humano, sendo o crescimento condição necessária, mas não suficiente. Assim sendo, utiliza-se, nesta pesquisa, a abordagem do desenvolvimento para além do crescimento, mas presa pela manutenção da importância deste último para o alcance de melhores níveis na qualidade de vida da população.

\subsection{Teoria do Crescimento Endógeno: o conhecimento como componente}

A teoria do crescimento endógeno é marcada por romper com a visão de crescimento econômico empregada nos modelos neoclássicos, o qual tem como fundamentos determinantes do processo de crescimento econômico os aspectos exógenos. Assim, essa teoria busca explicar que a geração de riqueza de uma economia deve-se dar por meio dos seus recursos internos, sejam eles capital físico ou capital humano.

Não obstante, torna-se fundamental que os atores envolvidos no processo estejam alinhados no mesmo sentido, qual seja, o crescimento econômico. Dessa forma, os elementos internos da economia são os responsáveis por conceder os meios suficientes para alavancar a melhoria econômica do espaço a que se refere. Nesse sentido, Souza (2009, p. 77) explica que:

a teoria do crescimento endógeno, similarmente à teoria dos pólos, afirma que a região tem dentro de si as fontes de seu próprio crescimento. É o meio que cria as condições para atrações de capitais de outras áreas e isso se torna ainda mais importante em "tempos de globalização".

Com isso, torna-se evidente que o esforço se dá de forma coletiva, mas principalmente com o planejamento de estratégias capazes de realçar esses atores que são determinantes para poder acontecer essa política que se faz de baixo para cima, contrariando todos os movimentos até então existentes. Barquero (2002) é 
enfático no assunto ao afirmar que os atores locais são extremamente relevantes, haja vista que são aqueles que conhecem os problemas e soluções mais de perto e, dessa forma, podem direcionar ações mais eficientes e eficazes, estimulando o segmento produtivo da economia, bem como garantindo o bem-estar social por meio da adoção de políticas públicas adequadas.

O simples fato da presença de grandes empresas motrizes e investimentos federais não são o suficiente para a ocorrência de um desenvolvimento local, fazendo-se necessária a observação da realidade regional a fim de que implementações de ações desenvolvimentistas partam de unidades pequenas e médias em âmbito local.

Pensando nisso, os teóricos Silva Filho e Carvalho (2001) esclarecem que, para que o crescimento endógeno aconteça de fato, deve ser eliminada a tendência decrescente de retorno de capital. A inovação tecnológica endógena, o capital humano e os arranjos institucionais assumem papel crucial nessa eliminação, uma vez que se forma um crescimento contínuo da renda per capita, seja em qual for o regime econômico.

Na mesma linha de raciocínio pensa Silva (2004, p. 78), mas enfatiza o capital humano no processo de crescimento econômico, principalmente ao dizer que:

o crescimento endógeno corresponde à endogeneização do progresso técnico, entendido como o aumento da eficiência na utilização dos fatores convencionais de produção, assentando sua base conceitual na consideração do aumento do estoque de conhecimentos como sendo o verdadeiro motor do crescimento per capita, prioritariamente à acumulação de capital físico ou humano.

Portanto, o autor considera antes de qualquer coisa o estoque de conhecimento como o elemento principal e desencadeador do processo de crescimento econômico. Ainda, para ele, "O conhecimento é um bem público, portanto apresenta simultaneamente as características da não rivalidade - o seu consumo por um agente não afeta a quantidade disponível para os outros agentes, e da não exclusão - nenhum agente pode excluir os demais de consumi-lo ao mesmo tempo." (SILVA, 2004, p. 78).

Conforme Teixeira e Silva (2006), no modelo de crescimento econômico de Solow, o progresso tecnológico é extremamente relevante, mas é dado como uma variável exógena ao modelo, o que inspirou outros autores a buscar explicar esse fenômeno mais a fundo. Assim, buscou-se verificar as forças econômicas que dão base ao progresso tecnológico e, dentre os elementos verificados, a educação foi um deles. Portanto, mostrando que a função de produção com essa ponderação mostra-se muito parecida com aquela do modelo de Solow, com a diferença de considerar o progresso tecnológico contendo a educação como uma de suas funções e A como elemento endógeno, de acordo com a equação 1.

$$
Y=K^{\alpha} A(\delta H) L_{y}^{1-\alpha}
$$


A tecnologia, ao inferir nos dois fatores de produção e, ainda de acordo com Teixeira e Silva (2006, p. 7), a função de produção pode ser escrita como "[...] regressões das diferenças entre logaritmos [...]". Assim:

$$
\begin{gathered}
Y=A(\delta H) K^{\alpha} L_{y}{ }^{1-\alpha} \\
\ln Y=\ln A(\delta H)+\alpha \ln K+(1-\alpha) \ln L_{y}
\end{gathered}
$$

Com a substituição de $\alpha=\beta_{1}$ e $(1-\alpha)=\beta_{1}$, obtém-se:

$$
\left.\ln Y_{t}-\ln Y_{0}=\left[\ln A(\delta H)_{1}\right)-\ln A(\delta H)_{0}\right]+\beta_{1}\left(\ln K_{t}-\ln K_{0}\right)+\beta_{2}\left(\ln L_{t}-\ln L_{0}(2)\right.
$$

Enfim, partindo dessas discussões, evidencia-se que o conhecimento, por meio do capital intelectual, apresenta-se como um dos principais componentes do crescimento econômico. A teoria do crescimento endógeno mostra a relevância de associar a educação como meio impulsionador da renda, uma vez que é determinante e possui características inerentes que permitem um processo acelerado de expansão, bem como difusão mais rápida por toda a região e com resultados mais proeminentes, principalmente, no longo prazo, por meio do progresso tecnológico.

\subsection{Externalidades e Educação}

Os efeitos da educação podem se dar de diversas formas dentro de uma economia, seja impactando diretamente no bem-estar das pessoas, seja proporcionando um crescimento econômico via aumento da renda ou mesmo impactando no entorno ao qual esteja se desenvolvendo. Esses resultados podem ser determinantes no contexto regional das economias que congregam do mesmo espaço geográfico, de forma a sofrerem externalidades educacionais.

O conceito de externalidade é tratado por Parkin (2009, p. 342) como "Um custo ou benefício que resulta da produção e incide em alguém que não é o produtor ou que resulta do consumo e incide em alguém que não é o consumidor [...]". Nesse mesmo sentido, Varian (1992, p. 432) fala que:

when the action of one agent directly affect the environment of another agent, we will say that there is an externality. In a consumption externality the utility of one consumer is directly affected by the actions of another consumer. For example, some consumers may be affected by other agents' consumption of tobacco, alcohol, loud music, and so on. Consumers might also be adversely affected by firms who produce pollution or noise.

O sistema educacional, por sua vez, provoca efeitos para além daqueles locais no qual se desenvolve, transpassando para locais circunvizinhos, influenciando positivamente na vida das pessoas que dele se utilizam. $O$ aumento do nível educacional permite elevadas taxas de produtividade tanto das pessoas que foram atores do processo de desenvolvimento educacional como daqueles que 
estão ao seu redor, uma vez que é facilitado o desenvolvimento das atividades via aumento da capacidade produtiva.

Para Amorim e Correia Neto (2012, p. 5):

[...] Se um nível educacional mais alto tornar a população capacitada em um nível mais técnico, então, toda a sociedade estará sendo beneficiada (e indiretamente o próprio Estado). Gruber argumenta que os benefícios sociais resultante da produtividade ocorrem por meio de dois canais: o primeiro refere-se ao 'transbordamento de produtividade' [...]. O segundo é que se a aquisição de educação pelo trabalhador em questão resultar em maior produtividade, então é o governo que arrecadará mais impostos.

Sem esquecer que a educação permite aumentar a qualidade de vida, torna os cidadãos mais esclarecidos e críticos, bem como participativos dos processos de decisões coletivas da sociedade à qual pertence. Essas ações provocam, de forma indireta, uma melhoria do bem-estar social de todos, pois possibilita uma intervenção direta nos ambientes políticos por buscas de melhorias e, assim, fortalece o processo democrático.

As externalidades oriundas da educação, na sua maioria, são positivas, uma vez que impactam no aumento de renda das famílias que, por sua vez, permitem elevação do padrão de vida e, desta forma, todas as pessoas envolvidas nesse contexto são beneficiadas. De outro modo, a educação permite um aumento do crescimento econômico de longo prazo, haja vista fazer com que a produtividade marginal incorporada pela qualificação da mão de obra seja aumentada e este processo é permanente.

Por outro lado, alguns autores explicam que o aumento do nível educacional pode provocar efeitos negativos, como é o caso do aumento da desigualdade na melhoria do capital humano, que, para Ferreira e Veloso (2003), essa elevação da desigualdade da qualidade da mão de obra faz com que se tenha uma maior desigualdade de renda e de oportunidades. Portanto e diante de todo o exposto, ficam evidentes que os efeitos de transbordamentos proporcionados pela educação têm estreitas implicações diretas no lado econômico. O aumento da produtividade e da renda são resultados de um processo educacional melhorado, implicando diretamente no crescimento econômico seja de uma cidade, região ou país. Não obstante, um aumento da qualificação profissional permite um desenvolvimento sustentado do bem-estar social.

\section{METODOLOGIA}

\subsection{Análise Exploratória de Dados Espaciais - AEDE}

Almeida (2012) explica que na econometria espacial, não diferente da econometria convencional, é necessário se fazer uma análise exploratória de dados, mas no caso de dados espaciais, visando identificar os efeitos de heterogeneidade espacial e dependência espacial, uma vez que estes efeitos implicam em entraves na especificação de modelos econométrico-espaciais de forma adequada. Conforme o autor, a AEDE trata-se de um conjunto de técnicas utilizadas para descrever e 
visualizar distribuições espaciais, bem como verificar locais com diferenciação dos demais, o que ele chama de outliers espaciais, e clusters espaciais, ou seja, padrões espaciais.

Visando calcular a autocorrelação espacial, foi utilizada a estatística de I de Moran. De acordo com Almeida et al. (2008, s/n),

\begin{abstract}
essa é uma estatística que fornece de maneira formal o grau de associação linear entre os vetores de valores observados em um tempo $t$ (zt) e a média ponderada dos valores dos seus vizinhos, ou os lags espaciais (Wzt) como são mais conhecidos na literatura. Valores do I de Moran maiores ou menores do que o valor esperado $E(I)=-1 /(n-1)$ revelam autocorrelação espacial positiva ou negativa, respectivamente.
\end{abstract}

A interpretação do valor do índice de Moran, segundo Marques et al. (2010), é no mesmo sentido da interpretação feita ao numerário de correlação entre duas variáveis aleatórias. Os autores explicam que o índice varia entre o intervalo de -1 a +1 , em que os resultados iguais a zero indicam a inexistência de autocorrelação espacial, enquanto que valores próximos a zero correspondem a autocorrelação espacial não significativa, entre o valor do atributo do objeto e o valor médio do atributo de seus vizinhos.

Quando o I de Moran apresentar valores positivos, é confirmada a presença de autocorrelação positiva, na qual se verifica que o valor do atributo do objeto tende a ser semelhante aos valores dos seus vizinhos. Já se observados valores negativos, o valor do atributo em uma região não é dependente dos valores dessa mesma variável em áreas diferentes, portanto, a presença de autocorrelação espacial negativa.

A estatística é obtida a partir da formulação expressa em (3),

$$
I=\frac{1}{\sum_{i \neq j} W_{i j}} \sum_{i \neq j} W_{i j}\left(\frac{y_{i}-\bar{y}}{S_{y}}\right)\left(\frac{y_{i}-\bar{y}}{S_{y}}\right)
$$

em que wij representa a matriz de pesos espaciais; yi é o valor do atributo considerado no município i; $\bar{y}$ representa o valor médio do atributo em foco. Com a seguinte regra de decisão estatística, para a hipótese de que os dados se distribuem aleatoriamente no espaço: $H_{0}: I=E(I)$ VS $H_{1}: I \neq E(I)$. Sendo que se $I>E(I)$, então ocorre autocorrelação espacial positiva; caso $I<E(I)$, ocorre autocorrelação negativa; se se $I=E(I)$, ausência de autocorrelação.

Quando o I de Moran apresentar valores positivos é confirmada a presença de autocorrelação positiva. Já se observados valores negativos o valor do atributo em uma região não é dependente dos valores dessa mesma variável em áreas diferentes, portanto, a presença de autocorrelação espacial negativa.

Em se tratando da matriz de pesos espaciais $(W)$, verifica-se que é utilizada para identificar a interdependência entre unidades espaciais. Dentre suas características, destaca-se por ser quadrada e não estocástica, de maneira que seus elementos wij demonstram a intensidade da associação existente entre cada par de 
unidades i e j. Dessa forma, capta os efeitos de contiguidades e vizinhança sobre os dados analisados.

Anselin (1988) ensina que para facilitar a interpretação da matriz (W) é necessária a padronização dos seus valores, de forma que cada elemento desta seja dividido pela soma total da linha à qual pertence, de forma que a soma de cada linha da matriz padronizada seja igual a 1. Almeida et al. (2006) evidencia que, com essa normalização, a matriz de pesos espaciais pode ser expressa por:

$$
I_{t}=\left(\frac{Z_{t}^{\prime} W Z_{t}}{Z_{t}^{\prime} Z_{t}}\right)
$$

Onde: $t=\{1,2 \ldots n\}$

Haddad e Pimentel (2004) explicam que, na literatura, existem várias formas de se fazer a matriz de pesos espaciais, no entanto, as do tipo Rainha (Queen) e Torre (Rook) são as mais utilizadas.

Com isso, apresenta-se formalmente, considerando-se $\mathrm{N}$ regiões da seguinte maneira:

$$
W=\left[\begin{array}{ccc}
W_{11} & \cdots & W_{1 N} \\
\vdots & \ddots & \vdots \\
W_{N 1} & \cdots & W_{N N}
\end{array}\right]
$$

em que $W_{i j}$ é a influência que o município i exerce sobre o município j.

Almeida (2012) fala que o diagrama de dispersão de Moran apresenta-se como uma alternativa para observação de autocorrelação espacial, uma vez que evidencia a defasagem espacial da variável de interesse no eixo vertical e o valor da variável de interesse no eixo horizontal. Conforme o autor, o diagrama fornece várias informações pertinentes, sendo uma delas quadrante de quatro tipos de associação linear espacial, sendo eles, Alto-Alto (AA), Baixo-Baixo (BB), Alto-Baixo $(A B)$ e Baixo-Alto (BA).

Contudo, o I de Moran Global apresenta limitações, tanto na sua representação por meio do diagrama ou mesmo por mapa de dispersão. Almeida (2012) explica essa diferença metaforicamente ao dizer que um pesquisador, ao trabalhar com uma floresta, precisa traçar um retrato dela inteira, porém, também se faz necessário ter um retrato de cada árvore que a compõe. Sendo assim, o I de Moran permite avaliar apenas a floresta como um todo.

Diante disso, serão utilizados os indicadores de autocorrelação espacial local que examinam os padrões de associação com maiores detalhes. Na concepção de Resende e Silva (2007) o teste LISA é adequado, pois indica se existe ou não uma distribuição espacial de uma variável qualquer em nível local e esta característica do teste detecta a da presença de clusters para uma dada variável em um determinado espaço, no qual é representado pela expressão (6).

$$
I_{\text {Local }}=\frac{Z_{i}}{\frac{\sum_{i}^{n} Z_{i}^{2}}{N}} \sum_{j \in j i}^{n} W_{I J} Z_{j}
$$


Onde: $\mathrm{N}$ é o tamanho amostral, Zi é o valor da variável $\mathrm{Z}$ na região i da variável normalizada; Ji é o conjunto de regiões vizinhas a i; Wij matriz de pesos $\mathrm{W}$. Interpretação: Se, Z(II) > 0, clusters de valores similares ao redor de i; $Z(I I)=0$, ausência de clusters; $\mathrm{Z}(\mathrm{II})<0$, clusters de valores dissimiles ao redor de i.

\subsection{Modelos espaciais}

Para verificar as implicações espaciais do desenvolvimento educacional com o crescimento econômico na Amazônia Clássica brasileira, na intencionalidade de identificar a ocorrência de spillovers espaciais entre os municípios, foi utilizada a metodologia de Cruz, Menezes e Ratton Júnior (2013). Os modelos espaciais estimados foram os SAR, SDM e SAC, caracterizados como modelos de regressão linear capazes de verificar influência das características das observações vizinhas em uma localidade próxima.

Com a definição da matriz de pesos espaciais, faz-se necessária a escolha da forma funcional do modelo. Partindo do modelo clássico, no qual apresenta uma determinada característica diretamente correlacionada com um conjunto de regressores somado a um termo aleatório, verifica-se a sua forma como na expressão (7).

$$
\mathrm{y}=\mathbf{X} \beta+u
$$

em que, "y" é o vetor $\mathrm{n}$ por 1 da variável dependente, $\mathrm{X}$ é a matriz $\mathrm{n}$ por $\mathrm{k}$ das variáveis independentes, $\beta$ é um parâmetro a ser estimado e "u", o termo de erro. Havendo algum tipo de dependência espacial, ou nos regressores ou no regressando, os estimadores $(\beta)$ de MQO serão viesados surgindo o entrave de endogeneidade. Por outro lado, se a dependência espacial se apresentar no termo de erro, os estimadores de MQO não se apresentarão viesados, porém inconsistentes (LESAGE e PACE, 2009).

Na busca de observar spillovers na variável dependente, utilizou-se o modelo Spatial Autoregressive Model (SAR). Conforme Anselin e Bera (1998), pode haver a inclusão de variáveis independentes sem que ocorra interferência espacial no modelo, sendo este modelo nomeado pelos autores como mixed regressive-spatial autoregressive model e assumindo a forma funcional seguinte:

$$
y=(I-\rho \mathbf{W})^{-1}(\mathbf{X} \beta+u)
$$

em que no modelo, no qual tem "n" observações e "k" parâmetros, "y" é um vetor de dimensão $\mathrm{n}$ por $1, \mathbf{W}$ é a matriz de vizinhança de ordem $\mathrm{n}$ por $\mathrm{n}, \mathbf{X}$ é uma matriz $\mathrm{n}$ por k, " $\beta$ " é o vetor de parâmetros de dimensão $k$ por 1 , " $u$ " é um vetor $n$ por 1 e a medição do grau de dependência espacial dado por " $\rho$ ". Compreendendo a influência das características representadas por "y" entre os vizinhos tem-se o termo $\rho \mathbf{W}$ y também usualmente chamado de lag espacial. Na ocasião em que coeficiente " $\rho$ " não seja significante, temos o modelo clássico de MQO. 
Considerando o trâmite de geração de dados, pode ser verificada a dependência espacial não somente na variável dependente, ou seja, além do lag espacial do regressando, pode ocorrer simultaneidade nos spillovers espaciais de origem dos regressores omitidos no termo de erro, devendo, assim, ser apresentados na equação do modelo. Dessa forma, o modelo que comporta a dependência espacial, tanto na variável dependente quanto no termo de erro, é chamado de Spatial Durbin Model (SDM) e é expresso em (9).

$$
\mathrm{y}=(\mathrm{I}-\rho \mathbf{W})^{-1}(\mathbf{X} \beta+\mathbf{W} \mathbf{X} \gamma+u)
$$

Os autores Lesage e Pace (2009), evidenciam que se " $\gamma=0$ ", o feedback espacial do regressor para observações vizinhas não existe e, portanto, o modelo passa a equivaler a um SAR. Cabendo ressaltar que o termo de erro segue uma distribuição normal e apresenta matriz de covariância homoscedástica, isto é: $u$ $\mathrm{N}\left(0, \sigma^{2} \mathrm{I}\right)$, tanto no modelo SAR quanto no SDM.

Verifica-se que em determinadas circunstâncias a dependência espacial manifesta-se apenas no termo de erro. Para tanto, deve-se utilizar o modelo Spatial Error Model (SEM). A grande dificuldade deste modelo está na interpretação dos dados, uma vez que os fatores que apresentam a dependência espacial não são controlados pelo usuário, o que de fato não acontece com os dois modelos vistos anteriormente. De todo modo, o modelo SEM é dado pela notação seguinte:

$$
\mathrm{y}=\mathbf{X} \beta+\varepsilon
$$

onde " $\varepsilon$ " é o termo de erro com processo espacial autorregressivo n por 1. Dentro dessa disturbância, encontra-se um erro totalmente aleatório, conforme em (11):

$$
\varepsilon=\lambda \mathbf{W} \varepsilon+u
$$

em que $\mathbf{W}$ é a matriz de pesos $\mathrm{n}$ por $\mathrm{n}$, “ $\lambda$ " é o coeficiente espacial e " $u$ ", o erro aleatório $n$ por 1 . Substituindo (10) em (11) temos:

$$
\mathrm{y}=\mathrm{X} \beta+(\mathrm{I}-\lambda \mathbf{W})^{-1} u
$$

Outro modelo imprescindível na análise é o SAC, pois incorpora a dependência espacial tanto no termo de erro como na variável dependente, sendo uma combinação do SAR e SEM. Este modelo é expresso na forma funcional de acordo com (13).

$$
\mathrm{y}=\rho \mathbf{W}_{\mathbf{1}} \mathbf{y}+\mathbf{X} \beta+\varepsilon \text {, onde } \varepsilon=\lambda \mathbf{W}_{\mathbf{2}} \varepsilon+u
$$

Fazendo as devidas substituições e desenvolvendo a equação, tem-se:

$$
\mathrm{y}=\left(\mathrm{I}-\rho \mathbf{W}_{\mathbf{1}}\right)^{-1} \mathbf{X} \beta+\left(\mathrm{I}-\lambda \mathbf{W}_{\mathbf{2}}\right)^{-1}\left(\mathrm{I}-\rho \mathbf{W}_{\mathbf{1}}\right)^{-1} u
$$


Em consonância com Lesage e Pace (2009), a matriz $\mathbf{W}_{1}$ pode ser igual à matriz $\mathbf{W}_{2}$, e o modelo então passa a ser reconhecido como Spatial Autoregressive Moving Average Model (SARMA).

Este trabalho se pautou da seguinte maneira: havendo a ocorrência de dependência espacial e seguindo Lesage e Pace (2009), bem como Almeida (2012), a estimação dos modelos se dará por Máxima Verossimilhança, considerando que a estimação por MQO, nesse caso, gera estimadores viesados e inconsistentes. Uma hipótese importante para gerar a função de verossimilhança é a de que o termo de erro segue uma distribuição normal com noise variance constante (homoscedástico). Com a estimação por Máxima Verossimilhança, os parâmetros estimados são assintoticamente consistentes e torna-se possível realizar inferência estatística.

Conforme Cruz, Menezes e Ratton Júnior (2013), o Multiplicador de Lagrange (LM) apresenta-se como o teste mais apropriado a indicar a especificação mais coerente para representar os dados. Esse, para Anselin et al. (2000), é um teste assintótico de mais uso na literatura de econometria espacial, haja vista necessitar da estimação do modelo apenas sob a hipótese nula. Fato notório é que ele pode ser realizado tanto na sua versão tradicional como robusta para os modelos que inserem lag espacial na variável dependente como naquele do termo de erro. No primeiro caso, temos as formas:

$$
\begin{gathered}
L M_{L a g}=\frac{\left(\frac{e \prime W y}{\left(e^{\prime} e\right) / n}\right)^{2}}{\frac{(W X \widehat{\beta}) \prime M(W X \widehat{\beta})}{\left(e^{\prime} e\right) / n}+t r\left(W \prime W+W^{2}\right)}, \\
R L M_{\text {lag }}=\frac{\left[\frac{e^{\prime \prime W y}}{\left(e^{\prime}(e) / n\right.}-\frac{e \prime W e}{\left(e^{\prime} e\right) / n}\right]^{2}}{\frac{(W X \widehat{\beta}) \prime M(W X \widehat{\beta})}{\left(e^{\prime} e\right) / n}+t r},
\end{gathered}
$$

onde " $t r$ " é o traço da matriz $M=\mathrm{I}-\mathrm{X}(\mathrm{X} \text { ' } \mathrm{X})^{-1} \mathrm{X}$ ' e " $\hat{\beta}$ " é o estimador de MQO. O teste com o modelo de erro espacial, nas versões tradicional e robusta, assume as seguintes funções:

$$
\begin{gathered}
L M_{e r r}=\frac{\left(\frac{e \prime W e}{\left(e^{\prime \prime e}\right) / n}\right)^{2}}{\operatorname{tr}\left(W \prime W+W^{2}\right)}, \\
R L M_{e r r}=\frac{\left[\frac{e \prime W e}{\left(e^{\prime} e\right) / n}-t r\left(\frac{(W X \widehat{\beta}) \prime M(W X \beta)}{\left(e^{\prime} e\right) / n}+t r\right)^{-1} \frac{e \prime W y}{\left(e^{\prime} e\right) / n}\right]^{2}}{t r-t^{2}\left(\frac{(W X \widehat{\beta}) \prime M(W X \beta)}{\left(e^{\prime} e\right) / n}+t r\right)^{-1}},
\end{gathered}
$$


Os coeficientes das variáveis independentes, em um modelo clássico de regressão linear, indicam a correlação parcial com o regressando, sendo a derivada parcial da variável dependente em relação à independente. Lesage e Pace (2009) informam que, quando se verificar que o processo gerador de dados incorpora a influência de vizinhos, a interpretação dos estimadores torna-se mais rebuscada, uma vez que a variável explicativa e/ou dependente defasada é capaz de afetar a sua própria região e também a de seus vizinhos geográficos.

Com a capacidade de ampliar o conjunto de informações para incluir outras oriundas de observações vizinhas, os modelos espaciais de regressão também são capazes de traduzir impactos estimados pelos efeitos diretos, indiretos e totais. Dessa maneira, é possível gerar esses efeitos por meio dos modelos SAR, SDM e SAC - pois o spillover é observável -, com isso, trazendo uma interpretação rica e intuitiva. A interpretação de dependência espacial nos modelos SEM, como discutido anteriormente, é muito difícil e cabe acrescentar que não é possível obter essas medidas de impacto, portanto, este modelo não será levado em consideração nesta pesquisa. Formalizando as três medidas citadas, temos:

Impacto Direto Médio - medida sumária que representa uma média dos efeitos de uma região "i" sobre ela mesma. Matematicamente é expressa como o traço da diagonal principal de $\mathrm{S}_{\mathrm{r}}(\mathrm{W})$, ou seja:

$$
\bar{M}(r)_{\text {direct }}=n^{-1} \operatorname{tr}\left(S_{r}(W)\right) \text {, }
$$

onde $S_{r}(W)=\left(I_{\mathrm{n}}-\rho \mathrm{W}\right)^{-1} \mathrm{I}_{\mathrm{n}} \beta_{\mathrm{r}}$, "n" é o número de observações, " $t r$ " é o traço da matriz e $\bar{M}(r)_{\text {direct }}$ é o efeito direto médio.

Impacto Total Médio - esta medida captura o impacto médio de todas as regiões incorporadas na matriz de vizinhança sobre uma determinada região "i", incluindo o seu próprio efeito. Pode ser expressa da seguinte maneira:

$$
\bar{M}(r)_{\text {total }}=n^{-1} \iota_{n}^{\prime} S_{r}(W) \iota_{n},
$$

onde $\iota_{n}$ é um vetor coluna unitário e $\bar{M}(r)_{\text {total }}$ é o efeito total médio.

Impacto Indireto Médio - Mede a influência das observações vizinhas sobre a região “i”, sendo obtida pela diferença entre os efeitos Total e Direto, ou seja:

$$
\bar{M}(r)_{\text {indirect }}=\bar{M}(r)_{\text {total }}-\bar{M}(r)_{\text {direct }},
$$

\subsection{Fonte de dados}

Os dados aqui utilizados foram todos secundários e retirados da plataforma oficial Atlas Brasil, Datasus e Instituto Brasileiro de Geografia e Estatística - IBGE. O índice de desenvolvimento educacional municipal é referente ao ano de 2010 e foi resultado do trabalho "Avaliação do desenvolvimento educacional dos municípios da região Norte do Brasil” realizado pelos autores Lobão e Silva (2016), e representa a variável dependente. O Produto Interno Bruto - PIB per capita, a taxa de pobreza, a taxa de desempregados, a taxa de trabalho infantil, renda média domiciliar per 
capita e o índice de GINI da renda média domiciliar per capita dos 449 municípios da região Norte foram coletados do Datasus, referente ao ano de 2010. Já a taxa de analfabetismo foi retirada do Atlas Brasil. Cabe destacar que os dados oriundos das plataformas Atlas Brasil, Datasus e IBGE são resultados do fornecimento de administradores dos municípios, portanto, podendo haver inconsistências nos mesmos.

A pesquisa tem como base o ano de 2010 para análise espacial do desenvolvimento educacional, porrepresentar o final do mandato de um governo que havia iniciado sua legislatura no ano de 2002.

\section{RESULTADOS E DISCUSSÕES}

\subsection{Análise Exploratória de Dados Espaciais - AEDE}

O nível de desenvolvimento educacional entre os municípios da Amazônia Clássica do Brasil apresenta uma grande disparidade na distribuição espacial, mostrando-se, portanto, de forma heterogênea, como mostra a figura 1. Verifica-se que as cidades com os melhores graus de desenvolvimento educacional encontramse no Estado de Rondônia, leste do Acre, norte do Amazonas, sul de Roraima, oeste do Pará e sul do Tocantins. Não obstante, os municípios com desenvolvimento educacional deficitário localizam-se mais a oeste da Região Norte, compondo, principalmente, os estados do Acre, Amazonas e Roraima.

Figura 1. Distribuição espacial do nível de desenvolvimento educacional na região norte em 2010

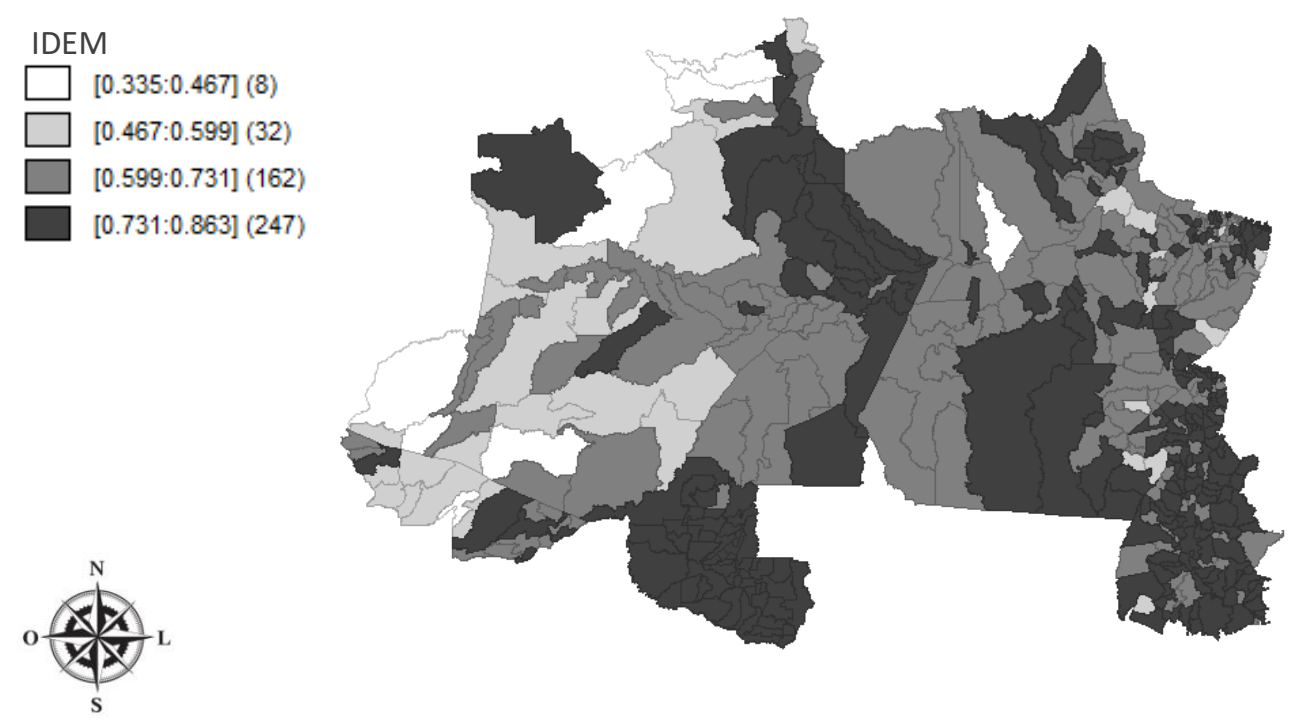

Fonte: Elaborado pelo autor.

A tabela 1 mostra os valores apresentados para o I de Moran tanto na matriz de contiguidade do tipo rainha quanto do tipo torre. Por meio da tabela 1, verifica-se 
claramente os indícios de presença de autocorrelação espacial positiva no índice de desenvolvimento educacional. Portanto, a estatística I de Moran permite rejeitar a hipótese nula de aleatoriedade espacial a um nível de significância de 1\%, a partir de testes com 9999 permutações.

Cabe destacar que o I de Moran percorre entre valores de -1 a 1. Caso o valor da estatística seja próximo de zero, identifica-se que inexiste autocorrelação espacial significativa entre os valores da região e seus vizinhos.

Tabela 1. I de Moran para o nível de desenvolvimento educacional dos municípios da Região Norte do Brasil, 2010

\begin{tabular}{ccc}
\hline CONTIGUIDADE & I DE MORAN & P-VALUE \\
\hline RAINHA & 0,4234 & 0,000 \\
TORRE & 0,4255 & 0,000 \\
\hline
\end{tabular}

Fonte: Resultados da pesquisa.

De acordo com a figura 2, constatam-se, em um nível de confiança de $95 \%$, que em algumas localidades da Região Norte existem certos padrões de autocorrelação espacial no nível de desenvolvimento educacional em 2010, Dessa forma, municípios com baixo desenvolvimento educacional que são próximo de outros também com baixo nível de desenvolvimento educacional (padrão baixobaixo) contabilizam em 47, sendo 08 no Estado do Acre, 29 no Amazonas, 02 em Roraima e 08 no Pará. O Estado de Tocantins e Amapá não apresentaram nenhum município com este padrão espacial.

Ao ser observado o padrão espacial dos municípios que apresentam alto nível de desenvolvimento educacional com vizinhos também com alto nível de desenvolvimento educacional (padrão alto-alto), percebe-se que estes estão na sua maioria nos estados de Rondônia e Tocantins. $O$ total das cidades com esse padrão é de 74, destas, 41 são do Estado de Rondônia, ou seja, mais de 50\% do total, 01 do Amazonas e 32 do Tocantins.

Figura 2. I de Moran Univariado Local do nível de desenvolvimento educacional da Região Norte do Brasil em 2010
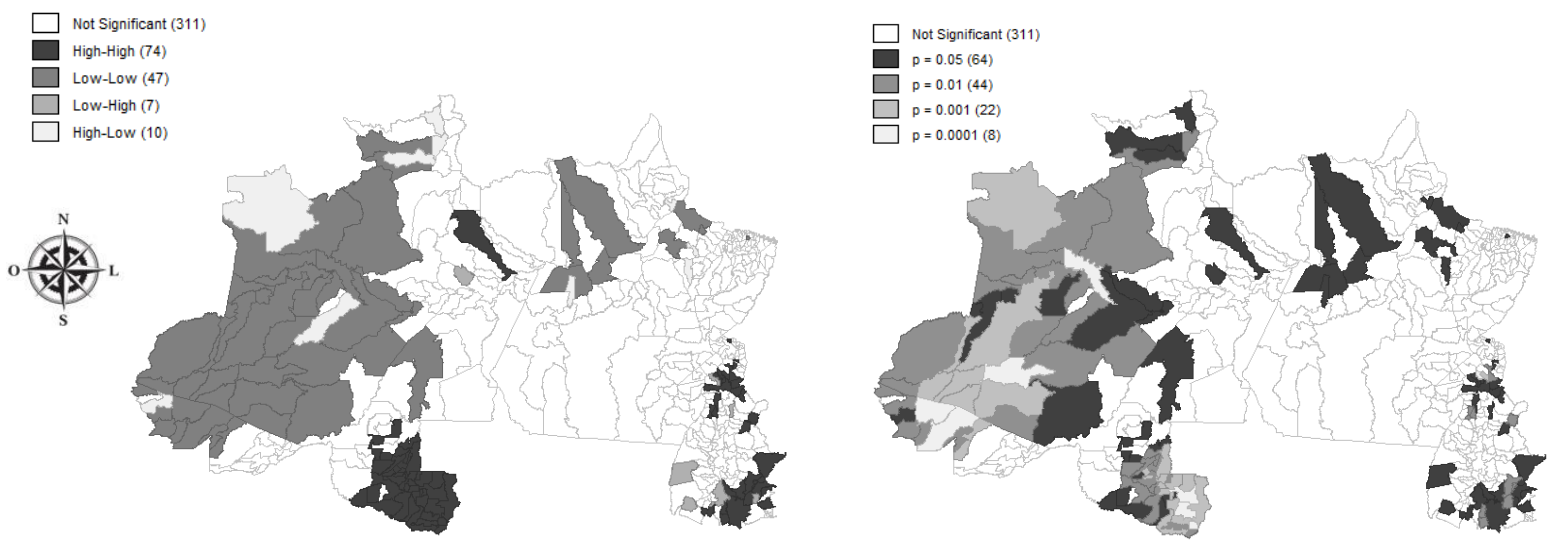

Fonte: elaborado pelo autor. 
Com a análise dos Clusters espaciais, por meio do I de Moran Univariado Local, é notório que a presença de spillovers educacionais existe entre municípios da Região Norte do Brasil. Destaca-se o oeste dessa região, que concentra quase a totalidade dos municípios que geram ou recebem externalidades educacionais negativas dos seus municípios vizinhos. Já no lado sul da região, encontra-se a maioria das localidades que impactam ou são impactadas positivamente pelo nível educacional das cidades circunvizinhas, com destaque para o Estado de Rondônia. Não obstante, esses transbordamentos educacionais são importantes informações para a concretização e viabilidade de aplicação de políticas públicas na área, haja vista poder trabalhar de forma direcionada e visando minimizar, principalmente, esses padrões espaciais do tipo baixo-baixo.

\subsection{Análise dos spillovers}

É perceptível com os resultados da tabela 02 que as variáveis explicativas referentes à porcentagem de pobres, à taxa de trabalho infantil e à taxa de analfabetismo nos municípios possuem uma relação muito significativa com o nível de desenvolvimento educacional, conforme os resultados da estatística t e p-valores baixos. Outro fato relevante é que essas três variáveis impactam negativamente, como mostram seus coeficientes. Já as variáveis PIB per capita, taxa de desemprego, índice de Gini da renda média domiciliar per capita e a renda média domiciliar per capita não mostraram significância e, portanto, evidenciando que não impactam no desenvolvimento educacional das cidades do norte brasileiro, o que será testado mais na frente por meio dos modelos espaciais.

Quanto às medidas de ajuste, o $\mathrm{R}^{2}$ indica que $75,76 \%$ da variância da variável dependente é capturado pelos regressores. Os resultados de diagnóstico revelam que não parece haver problema de multicolinearidade na regressão, uma vez que o valor do número condicional evidenciado encontra-se na faixa numerária dos 50 . No entanto, o teste Jarque-Bera esclarece que os resíduos não são normais, portanto, rejeita a hipótese nula de aleatoriedade espacial, e o teste Koenker-Basset indica a presença de heterocedasticidade no modelo. 
Tabela 02. Resultado das estimativas econométricas para os modelos de MQO

\begin{tabular}{|c|c|c|c|}
\hline \multirow[t]{2}{*}{ Variáveis } & \multicolumn{3}{|c|}{ MCLR } \\
\hline & & Coeficientes & t-estatísticas \\
\hline Constante & & $\begin{array}{c}1,018441 \\
(0,00000)^{+++}\end{array}$ & 46,8893334 \\
\hline POBRE & & $\begin{array}{c}-0,002356045 \\
(0,00000)^{+++}\end{array}$ & $-5,2233395$ \\
\hline PIB & & $\begin{array}{c}-3,811134 \mathrm{e}-008 \\
(0,90153)^{\mathrm{NS}}\end{array}$ & $-0,1238400$ \\
\hline TX_TRAB & & $\begin{array}{l}-0,001365461 \\
(0,00002)^{+++}\end{array}$ & $-4,3512461$ \\
\hline TX_DESEM & & $\begin{array}{c}-0,0001280116 \\
(0,82189)^{N S}\end{array}$ & $-0,2252668$ \\
\hline GINI & & $\begin{array}{l}-0,1033082 \\
(0,07033)^{\mathrm{NS}}\end{array}$ & $-1,8141922$ \\
\hline RMDPR & & $\begin{array}{c}-4,948433 \mathrm{e}-005 \\
(0,24959)^{\mathrm{NS}}\end{array}$ & $-1,1528715$ \\
\hline TX_ANALF & & $\begin{array}{c}-0,006557354 \\
(0,00000)^{+++}\end{array}$ & $-17,9884420$ \\
\hline $\mathrm{R}^{2}$ & \multicolumn{3}{|c|}{0,757571} \\
\hline $\mathrm{R}^{2}$ ajustado & \multicolumn{3}{|c|}{0,753723} \\
\hline AIC & \multicolumn{3}{|c|}{$-1571,99$} \\
\hline SC & \multicolumn{3}{|c|}{$-1539,14$} \\
\hline \multicolumn{4}{|c|}{ Diagnóstico } \\
\hline $\begin{array}{l}\text { Multicolinearidade } \\
\text { Jarque-Bera }\end{array}$ & \multicolumn{3}{|c|}{$\begin{array}{c}52,144784 \\
73,8507 \\
(0,00000)^{+++}\end{array}$} \\
\hline Koenker-Basset & \multicolumn{3}{|c|}{$\begin{array}{l}106,4150 \\
(0,00000)^{+++}\end{array}$} \\
\hline \multicolumn{4}{|c|}{ Dependência Espacial } \\
\hline & Rainha & Torre & K10 \\
\hline I de Moran & $\begin{array}{c}8,295 \\
(0,0000)^{+++}\end{array}$ & $\begin{array}{c}8,1835 \\
(0,0000)\end{array}$ & $\begin{array}{c}8,9142 \\
(0,0000)\end{array}$ \\
\hline ML (lag) & $\begin{array}{c}33,799 \\
(0,0000)^{+++}\end{array}$ & $\begin{array}{c}33,865 \\
(0,0000)\end{array}$ & $\begin{array}{c}24,411 \\
(0,0000)\end{array}$ \\
\hline ML Robusto (lag) & $\begin{array}{c}15,074 \\
(0,0001)^{+++}\end{array}$ & $\begin{array}{c}15,844 \\
(0,0001)\end{array}$ & $\begin{array}{c}12,176 \\
(0,0005)\end{array}$ \\
\hline ML (erro) & $\begin{array}{c}22,476 \\
(0,0000)^{+++}\end{array}$ & $\begin{array}{c}20,997 \\
(0,0000)\end{array}$ & $\begin{array}{l}17,644 \\
(0,0000)\end{array}$ \\
\hline ML Robusto (erro) & $\begin{array}{c}3,751 \\
(0,0052)^{+++}\end{array}$ & $\begin{array}{c}2,975 \\
(0,0846)\end{array}$ & $\begin{array}{l}5,409 \\
(0,0200)\end{array}$ \\
\hline
\end{tabular}

Fonte: Resultados da pesquisa.

Nota: Os valores entre parênteses são os $p$ valores.

+++ - Significativo a $1 \% \quad$ NS - Não significativo

Os testes de Multiplicador de Lagrange - ML, tanto na sua versão tradicional quanto robusto, apresentaram-se estatisticamente significativos. Considerou-se aquele com maior valor estatístico, portanto, conforme tabela 02, adotou-se o ML da defasagem. Ainda de acordo com os resultados desse teste, ficou comprovado algum tipo de dependência espacial por meio de lag-espacial, podendo encontrar algum efeito de spillover tanto em termos de desenvolvimento educacional para cidades vizinhas quanto dos fatores explicativos. Em relação à correlação nos termos de erros, o teste do ML não apresenta tanta significância, indicando, assim, uma autocorrelação baixa dos termos de erros espaciais. Portanto, o valor mais alto 
do teste de $M L$ na versão tradicional de dependência indica que um bom modelo é o SAR ou SAC.

Na situação de presença de não normalidade dos termos de erro, os testes de $M L$ são colocados sob suspeita e não representando um resultado de correlação espacial com segurança. Esse fato identifica a presença de variáveis endógenas com determinações simultâneas com o Índice de Desenvolvimento Educacional, no caso, o PIB per capita (PIB) e porcentagens de pessoas pobres (POBRES), levando a um viés de simultaneidade nos estimadores de MQO.

Para contornar este problema, utilizou-se a estimação por Variáveis Instrumentais para o modelo de Mínimo Quadrado de Dois Estágios, que, conforme Chasco (2013), baseia-se na existência de um conjunto de instrumentos que devem ser fortemente correlacionados com as variáveis explicativas endógenas originais, mas assimptoticamente não correlacionadas com o termo de erro. Como alternativa, utilizou-se a defasagem das variáveis endógenas, conforme indicação de Kelejian e Robinson (1992) e Kelejian e Pruncha (1998).

De acordo com a tabela 03 e seguindo o resultado do teste de AnselinKelejian, é permitido aceitar a anulação de autocorrelação espacial, uma vez que o teste não foi estatisticamente significativo.

Tabela 03. Resultado das estimativas econométricas para o modelo de MQ2E por Variáveis Instrumentais

\begin{tabular}{|c|c|c|}
\hline \multirow[t]{2}{*}{ Variáveis } & \multicolumn{2}{|c|}{ MQ2E } \\
\hline & Coeficientes & z-estatísticas \\
\hline Constante & $\begin{array}{c}1,1384049 \\
(0,0000)^{+++}\end{array}$ & 14,7048732 \\
\hline POBRE & $\begin{array}{l}-0,0194721 \\
(0,0173)^{+++}\end{array}$ & $-2,3783686$ \\
\hline PIB & $\begin{array}{c}-0,0000059 \\
(0,3089)^{\mathrm{NS}}\end{array}$ & $-1,0173730$ \\
\hline TX_TRAB & $\begin{array}{l}0,0006465 \\
(0,5839)^{N S}\end{array}$ & 0,5475814 \\
\hline TX_DESEM & $\begin{array}{l}0,0003799 \\
(0,7929)^{N S}\end{array}$ & 0,2624561 \\
\hline GINI & $\begin{array}{l}1,6217420 \\
(0,0477)^{N S}\end{array}$ & 1,9792036 \\
\hline RMDPR & $\begin{array}{l}-0,0013810 \\
(0,0234)^{N S}\end{array}$ & $-2,2666088$ \\
\hline TX_ANALF & $\begin{array}{l}-0,0059311 \\
(0,0000)^{+++}\end{array}$ & $-6,9954401$ \\
\hline \multicolumn{3}{|c|}{ Diagnóstico para Dependência Espacial } \\
\hline Anselin-Kelejian Test & & \\
\hline
\end{tabular}

Fonte: Resultados da pesquisa.

Nota: Os valores entre parênteses são os $p$ valores.

+++ - Significativo a $1 \% \quad$ NS - Não significativo 
Uma vez que existe a presença de regressores endógenos, a estimação dos modelos SAR, SAC e SDM se deu pelo Método de Variáveis Instrumentais, conforme tabela 04. Ao observar os resultados das estimações, identifica-se que somente 0 modelo SDM teve o parâmetro rhô significativo, demonstrando que existe a presença de spillover espacial tanto da variável dependente quanto das variáveis explicativas. Dessa forma, verifica-se que o nível de desenvolvimento educacional dos municípios da Amazônia Clássica geram externalidades positivas para seus municípios vizinhos e também sofrem externalidades educacionais positivas, explicando que a incidência de bom desenvolvimento educacional das cidades permitem com que outras localidades próximas sejam beneficiadas e influenciadas por este desenvolvimento. No modelo SAC, o coeficiente lambda não foi significante, mostrando que não foi captado influência espacial nos resíduos.

Para a análise das medidas sumárias, foi considerado o modelo SDM por ter apresentado a melhor configuração de variáveis, tanto dependente quanto explicativas, e por não ter havido a confirmação de presença de influência nos resíduos.

Com isso, verifica-se que tanto POBRES, TX_TRAB e TX_ANALF são determinantes no processo de melhoramento do índice educacional dos municípios do norte brasileiro. Não obstante, são indicações de que essas variáveis devem ser objetivo a ser perseguido pelos prefeitos e governadores de cada unidade municipal e estado da região Norte, uma vez que são variáveis que mais impactam na educação e de forma negativa.

Por outro lado, observa-se também a presença de transbordamentos ou externalidades negativas entre as cidades do Norte em relação à taxa de desemprego. Portanto, quanto maiores as taxas dessa variável em um município, maiores também são os impactos sofridos negativamente nos municípios vizinhos. Assim sendo, tornam-se necessários esforços coletivos na diminuição ou erradicação da taxa de desemprego, inclusive esses efeitos podem estar acontecendo tanto no âmbito dos municípios de um mesmo estado quanto de municípios de estados vizinhos que são contíguos. 
Tabela 04. Resultados das estimações dos modelos SAR, SAC e SDM

\begin{tabular}{|c|c|c|c|}
\hline \multirow[t]{2}{*}{ Coeficiente } & \multicolumn{3}{|c|}{ MQ2E } \\
\hline & SAR & SAC & SDM \\
\hline Constante & $\begin{array}{l}0,9331505 \\
(0,00000)^{+++}\end{array}$ & $\begin{array}{c}0,9685038 \\
(0,0003577)^{+++}\end{array}$ & $\begin{array}{c}0,3094901 \\
(0,1682321)^{\mathrm{NS}}\end{array}$ \\
\hline POBRE & $\begin{array}{r}-0,003384648 \\
(0,00000)^{+++}\end{array}$ & $\begin{array}{c}-0,0121215 \\
(0,4696795)^{N S}\end{array}$ & $\begin{array}{c}-0,0018603 \\
(0,0061514)^{+++}\end{array}$ \\
\hline PIB & $\begin{array}{c}0,0000003 \\
(0,4956143)^{N S}\end{array}$ & $\begin{array}{c}-0,0000055 \\
(0,5468045)^{\mathrm{NS}}\end{array}$ & $\begin{array}{c}-0,0000000 \\
(0,9316646)^{\mathrm{NS}}\end{array}$ \\
\hline TX_TRAB & $\begin{array}{c}-0,0008517 \\
(0,0255660)^{N S}\end{array}$ & $\begin{array}{c}-0,0001560 \\
(0,9380559)^{N S}\end{array}$ & $\begin{array}{c}-0,0010267 \\
(0,0010726)^{+++}\end{array}$ \\
\hline TX_DESEM & $\begin{array}{c}-0,0002559 \\
(0,6772688)^{\mathrm{NS}}\end{array}$ & $\begin{array}{c}0,0005897 \\
(0,6756963)^{N S}\end{array}$ & $\begin{array}{c}0,0001709 \\
(0,7573586)^{\mathrm{NS}}\end{array}$ \\
\hline GINI & $\begin{array}{c}0,3782662 \\
(0,0239194)^{\mathrm{NS}}\end{array}$ & $\begin{array}{c}0,9127296 \\
(0,5733163)^{N S}\end{array}$ & $\begin{array}{c}-0,0179929 \\
(0,8004760)^{\text {NS }}\end{array}$ \\
\hline RMDPR & $\begin{array}{c}-0,0004384 \\
(0,0023347)^{+++}\end{array}$ & $\begin{array}{c}-0,0007619 \\
(0,5346062)^{N S}\end{array}$ & $\begin{array}{c}-0,0000483 \\
(0,4221973)^{N S}\end{array}$ \\
\hline TX_ANALF & $\begin{array}{c}-0,0062111 \\
(0,0000000)^{+++}\end{array}$ & $\begin{array}{c}-0,0059706 \\
(0,0000000)^{+++}\end{array}$ & $\begin{array}{c}-0,0069313 \\
(0,0000000)^{+++}\end{array}$ \\
\hline lag. TX_TRAB & & & $\begin{array}{c}0,0001025 \\
(0,9106446)^{N S}\end{array}$ \\
\hline lag. TX_DESEM & & & $\begin{array}{c}-0,0025893 \\
(0,0000000)^{+++}\end{array}$ \\
\hline lag. GINI & & & $\begin{array}{c}0,1238475 \\
(0,0924575)^{N S}\end{array}$ \\
\hline lag. RMDPR & & & $\begin{array}{c}-0,0000858 \\
(0,2732403)^{\mathrm{NS}}\end{array}$ \\
\hline lag. TX_ANALF & - & - & $\begin{array}{c}0,0049178 \\
(0,0723939)^{N S}\end{array}$ \\
\hline Rho & $\begin{array}{c}0,1197561 \\
(0,0300195)^{\mathrm{NS}}\end{array}$ & $\begin{array}{c}0,1333462 \\
(0,4147994)^{\mathrm{NS}}\end{array}$ & $\begin{array}{c}0,7376103 \\
(0,0004374)^{+++}\end{array}$ \\
\hline Lambda & - & $\begin{array}{c}0,0824383 \\
(0,2883200)^{\mathrm{NS}}\end{array}$ & - \\
\hline
\end{tabular}

Fonte: Resultados da pesquisa.

Nota: Os valores entre parênteses são os $p$ valores.

+++ - Significativo a $1 \% \quad$ NS - Não significativo

Os efeitos diretos, indiretos e totais são necessários na análise porque, mesmo com viés gerado por variáveis omitidas, tornam-se pertinentes. Com isso, a tabela 05 mostra os resultados desses efeitos para as variáveis socioeconômicas com significância estatística referente ao modelo SDM. Cabe ressaltar que todas as três variáveis consideradas na análise apresentam efeitos diretos, indiretos e totais significativos a $1 \%$. Essa significância torna-se relevante uma vez que nenhum dos efeitos pode ser invalidado por algum efeito que não seja nulo.

É evidente que um grande adensamento da população considerada pobre em determinado município incide em efeito médio direto negativo sobre o nível de desenvolvimento educacional do ambiente em que reside, mesmo que a densidade de pobres dos municípios vizinhos não impacte no nível educacional dessa cidade (efeito indireto nulo). Isso se explica pelo fato dessas pessoas possuírem condições de vida que ou impossibilitem ou reduzem a possibilidade de uma boa educação em decorrência de sua limitação financeira. Considerando os efeitos indiretos da taxa 
de pobreza de um município em face de outro município vizinho, ou seja, os efeitos de spillovers, a situação é semelhante, haja vista que os impactos indiretos da taxa de pobreza afetam negativamente as cidades circunvizinhas.

Não é o caso de afirmar que o culpado pelo fracasso educacional em determinado município seja decorrente daquelas cidades que o rodeiam, mas também é o caso de considerá-las no rol de possibilidades de influências negativas para o desenvolvimento educacional do município em questão. Dessa maneira, o ideal seria que ambas as unidades municipais trabalhassem direcionadas para 0 mesmo sentido, pois assim uma melhora generalizada seria praticada e, consequentemente, com repercussões objetivas e eficazes em via de mão dupla.

Os efeitos diretos, indiretos e totais da taxa de analfabetismo e da taxa de trabalho infantil representam similaridades àqueles da taxa de pobreza. Portanto, os transbordamentos das duas variáveis geram externalidades negativas tanto nos municípios onde o fenômeno acontece quanto nas redondezas que lhe cercam. Dessa forma, o trabalho infantil e a quantidade de pessoas analfabetas pioram veementemente os índices e qualidade do desenvolvimento da educação em toda a Região Norte. Fato notório é que a presença de ilhas ou padrões espaciais que revelam graus de concentração dessas variáveis tendem a ser mais difíceis de serem contornadas, pois não se trata apenas de caso isolado, mas de um grupo de cidades que compartilham da situação negativa nos índices dessas variáveis, caracterizando a necessidade de um esforço coletivo na busca da otimização da aplicação de políticas públicas voltadas a área socioeconômica e que sejam realizadas de forma integrada.

Dessa maneira, a realização do desenvolvimento dessas políticas permitiriam benefícios multidirecionais, tanto no sentido geográfico, já que existe uma interação espacial neste contexto, como na melhoria dos índices educacionais, uma vez que tanto a taxa de analfabetismo quanto a taxa de trabalho infantil impactam diretamente na educação, assim como propriamente nas variáveis trabalhadas.

Tabela 05. Resultados dos Efeitos Direto, Indireto e Total do Modelo SDM

\begin{tabular}{cccc}
\hline & Efeito Direto & Efeito Indireto & Efeito Total \\
\hline POBRE & & & \\
T & $-0,0000053$ & $-0,0000140$ & $-0,0000194$ \\
TX_ANALF & $-2,7688569$ & $-2,3491991$ & $-3,5182462$ \\
T & $-0,0000188$ & $-0,0000489$ & $-0,0000677$ \\
TX_TRAB & $-14,2972542$ & $-2,6999417$ & $-3,7376110$ \\
T & $-0,0000027$ & $-0,0000070$ & $-0,0000097$ \\
\hline
\end{tabular}

Fonte: Resultados da pesquisa.

As estatísticas " $t$ ” estão representadas abaixo dos valores dos efeitos. Todos os valores são significativos a $1 \%$.

\section{CONSIDERAÇÕES FINAIS}

A pesquisa teve como objetivo verificar a existência de spillovers educacionais nos municípios da Região Norte, tendo como proxy o nível de desenvolvimento educacional dos municípios do norte brasileiro, considerando a pouca fonte de informações empíricas a esse respeito e em nível tão desagregado 
quanto as cidades. Nessa perspectiva, a análise mostrou-se relevante por ter incluído informações sobre o ambiente com o auxílio de um banco de dados atual, referente ao último Censo Brasileiro (2010). Analisou-se como os fatores socioeconômicos estão associados ao grau de educação das cidades.

O olhar principal pautou-se no sentido de evidenciar as correlações entre os fatores sociais e econômicos sobre o nível de desenvolvimento educacional das cidades da Região Norte, considerando que são recorrentes em estudos econômicos dificuldades provenientes de viés de variável omitida de qualquer natureza. Ademais, exigiu-se técnicas estatísticas diferentes para tratar a questão. Dentro desse contexto, para contornar o viés de variável espacial omitida, foi proposta a metodologia de econometria espacial a fim de investigar os efeitos das observações vizinhas.

Verificou-se, inicialmente, com os resultados do I de Moran, a presença de uma autocorrelação positiva do Indicador de Desenvolvimento Educacional. Desta forma, municípios com baixo desenvolvimento educacional são próximos de outros também com baixo nível de desenvolvimento educacional (padrão baixo-baixo) e contabilizam 47 do total, sendo 08 no Estado do Acre, 29 no Amazonas, 02 em Roraima e 08 no Pará. Tocantins e Amapá não apresentaram nenhum município com esse padrão espacial.

Em relação ao padrão espacial de alto nível de desenvolvimento educacional com vizinhos também com alto nível de desenvolvimento educacional (padrão altoalto), percebe-se que estes estão na sua maioria nos estados de Rondônia e Tocantins. A totalidade dos municípios com esse padrão foi de 74 , sendo que 41 destes se encontraram no Estado de Rondônia, isto é, mais de 50\% do total, 01 do Amazonas e 32 do Tocantins.

Com a regressão do modelo SDM, foram obtidos resultados que demonstraram relação tanto direta como indireta da educação com variáveis socioeconômicas. Na Amazônia Clássica brasileira, observa-se que, nas cidades onde a proporção de pobres em relação ao total de residentes é maior, predomina um baixo nível educacional e uma possível explicação para isso é que a condição financeira dessas pessoas as limita de um acesso à educação de qualidade.

O resultado da estimação para a análise dos impactos provenientes das variáveis que expressam a taxa de analfabetismo e trabalho infantil só demonstraram, de forma contundente, aquilo que era de se esperar. É notório que esses dois eventos sociais representam significativamente e de forma negativa tanto na cidade que se desenvolvem quanto em cidades vizinhas, mostrando que os efeitos diretos, indiretos e totais proporcionam analisar com maior cautela e preocupação estes fenômenos na busca de minimizá-los. Acredita-se que os impactos negativos de pessoas analfabetas sobre a taxa geral de desenvolvimento educacional seja decorrente de que pessoas menos esclarecidas acabam por se tornarem apenas coadjuvantes na sociedade em que estão inseridas, bem como podem desencadear uma reprodução social do seu estágio educacional, como muito se vê nas comunidades interioranas da Amazônia, realçando aquilo que Myrdal (1968) vai chamar de círculo vicioso e de retroalimentação social. Já a referência negativa para o nível educacional dos municípios em relação ao trabalho infantil está no fato deste cercear a criança de frequentar a escola e se desenvolver 
nos estudos, de acordo o andamento normal vigente. Como tudo é um elo que se liga desde o momento da família à sociedade, a partir do momento que esta criança deixa de participar da educação formal, passa-se a representar na fase adulta uma parcela ativa da taxa de analfabetos, ou seja, existe um efeito em cascata entre as variáveis, o qual deve ser eliminado na origem por meio de políticas públicas.

Com isso, a busca por menores taxas ou mesmo erradicação da pobreza, do analfabetismo e do trabalho infantil nos municípios do norte brasileiro é condição sine qua non para a elevação do nível de desenvolvimento da educação desta região. As cidades não se apresentam como unidades isoladas no espaço, pois estão interligadas e produzindo ou sofrendo efeitos espaciais (spillovers) relevantes para toda a região. As influências se mostraram aparentemente mais correlacionadas com efeitos diretos, indiretos e totais negativos, de maneira a sinalizar a pactuação de forma convergente entre as cidades do norte brasileiro, no sentido de minimizar ao máximo os efeitos das pessoas que vivem na pobreza, que são analfabetas ou com crianças trabalhando, portanto, reduzindo o grau dessas variáveis que são tão importantes para reverberar a situação adversa da educação das cidades e, consequentemente, gerar efeitos positivos no contexto regional dentro da perspectiva de desenvolvimento econômico nacional.

Assim sendo, este trabalho empreendeu-se no esforço de mostrar que as políticas de desenvolvimento socioeconômica na região amazônica têm tido impactos diretos e indiretos na promoção do desenvolvimento educacional e a superação da condição de subdesenvolvimento das comunidades que ali residem. Afinal, o desenvolvimento acontece com e para as pessoas. Não obstante, é a partir da promoção educacional que se consegue a superação da condição de pobreza e do analfabetismo, portanto, a transposição das privações de liberdades, tanto defendida pelo teórico Amartya Sen (2000), o desenvolvimento como liberdade.

\section{REFERÊNCIAS}

ALMEIDA, E. Econometria Espacial Aplicada. Campinas: Alínea, 2012.

ALMEIDA, S. de M.; TEIXEIRA, R. F. A. P.; FERNANDES, H. S.; OLIVEIRA JÚNIOR, L. B. de; Análise espacial da plantação de oleaginosas para a produção de biodiesel. In: Congresso da Sociedade Brasileira de Economia, Administração e Sociologia Rural. 46. 2008. Rio Branco. Disponível em: http://www.sober.org.br/palestra/9/440,pdf. Acessado em: 20 ago. 2014.

AMORIM, P. de J; CORREIA NETO, S. J. Externalidades da educação no Brasil: entre o público e o privado. In: Congresso Nacional de Excelência em Gestão, 8., 2012, Niterói. Anais. Disponível em: <http://www.excelenciaemgestao.org/Portals/2/documents/cneg8/anais/T12_0473_2 978.pdf>. Acessado em: 09 ago. 2014.

ANSELIN, L. Spatial econometrics: methods and models. Kluwer. Academic, Boston, 1988, 284p. 
.Local Indicator of Spacial Association-LISA. Geographical Analysis, 27:93-115, 1995.

ANSELIN, L.; BERA, A. Spatial dependence in linear regression models with an introduction to spatial econometrics. In: Handbook of applied economic statistics, edited by Amman Ullah and David E.A. Giles. New York: Marcel Dekker. 1998.

ANSELIN, L.; COHEN, J.; COOK, W. G.; TITA, G. Spatial Analyses of Crime.

Measurement and Analyses of Crime and Justice, Criminal Justice, vol 4, 2000,

BAGOLIN, Izete Pengo; PORTO JÚNIOR, Sabino da Silva. A desigualdade da distribuição da educação e crescimento no Brasil: índice de GINI e anos de escolaridade. Salão de Iniciação Científica (15. : 2003 : Porto Alegre). Livro de resumos. Porto Alegre : UFRGS, 2003. Disponível em: <

http://www.ufrgs.br/ppge/pcientifica/2003_09.pdf>. Acessado em: 05 ago. 2014.

BARQUERO, Antônio Vásquez. Desenvolvimento endógeno em tempos de globalização. Porto Alegre: Editora da UFRGS, 2002.

CHASCO, Coro. GEODASPACE: a resource for theaching spatial regression models. Departamento de Economia Aplicada, Universidad Autónoma de Madrid. 2013.

CRUZ, G. T.; MENEZES, T. A.; RATTON JÚNIOR, J. L. de M.; Estudo da criminalidade violenta na cidade do recife: o espaço realmente é relevante?In: Encontro Nacional de Economia. 41. 2013. Recife. Anais. Disponível em< http://econpapers.repec.org/paper/anpen2013/173.htm>. Acessado em: 29 ago. 2014.

FERREIRA, S. G.; VELOSO, F. Economia Brasileira Contemporânea Brasileira. Organizadores: Giambiagi et al. Rio de Janeiro: Campus, 2005.

FURTADO, C.. Pequena introdução ao desenvolvimento: enfoque interdisciplinar. São Paulo: Ed. Nacional, 1980.

JONES, Charles L. Introdução à Teoria do Crescimento Econômico. Rio de Janeiro: Campus, 2000,

LESAGE, J.; PACE, R. K. Introduction to Spatial Econometrics, CRC Press, 2009.

LOBÃO, M. S. P.; SILVA, R. G. da. Avaliação do desenvolvimento educacional dos municípios da região Norte do Brasil. Revista Brasileira de Desenvolvimento Regional, Blumenau, vol. 2, nº4, p. 93-120, primavera de 2016. Disponível em: <http://proxy.furb.br/ojs/index.php/rbdr/article/view/5385/pdf>. Acessado em: 20 dez. 2016. 
MARQUES, A. P da S.; HOLZSCHUH, M. L.; TACHIBANA, V. M.; IMAI, N. N. Análise exploratória de dados de área para índices de furto na mesorregião de Presidente Prudente-SP. In: Simpósio Brasileiro de Ciências Geodésicas e Tecnologias da Geoinformação. 3. 2010, Recife, p. 001-008. Disponível em: <http://www.ufpe.br/cgtg/SIMGEOIII/IIISIMGEO_CD/artigos/CartografiaeSIG/SIG/A_2 23.pdf $>$. Acessado em: 23 ago. 2014.

MYRDAL, G. Teoría económica y regiones subdesarrolladas. México: Fondo de Cultura Económica, 1968.

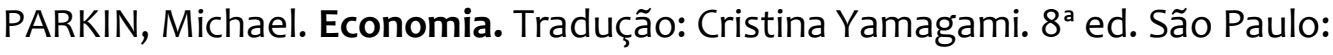
Addison Wesley, 2009.

PEREIRA, Josafá Machado. Educação x Crescimento Econômico: um estudo sobre os investimentos governamentais em educação na Região Norte do Brasil no período de 1994-2004. Monografia (Graduação) - Fundação Universidade Federal do Tocantins, Palmas, defendida em 10 de junho de 2008, 69 folhas. Disponível em:< http://www.eumed.net/libros-

gratis/2010C/717/EDUCACAO\%20X\%20CRESCIMENTO\%20ECONOMICO\%20RESUMO.ht m>. Acessado em: 05 ago. 2014.

PIMENTEL, E. A.; HADDAD, E. A. Análise da distribuição espacial da renda no Estado de Minas Gerais: uma abordagem setorial. 2004. Disponível em: <http://www.econ.fea.usp.br/nereus/td/Nereus_02_04.pdf>. Acessado em: 23 ago. 2014.

RESENDE, G. M. ; SILVA, A. M. A.. Crescimento econômico dos municípios da Região Sul do Brasil: uma análise espacial. Ensaios FEE, v. 28, p. 549-576, 2007.

SALVADOR, F. M; GARGALLO, P. Análisis Exploratorio de Datos.[en línea] 5campus.com,Estadística, 2003. Disponível em <http://www.5campus.com/leccion/aed>. Acessado em: 10 ago. 2014.

SEN, A. K. Desenvolvimento como liberdade. São Paulo: Companhia das Letras, 2000.

SILVA FILHO, Guerino Edécio da; CARVALHO, Eveline Barbosa Silva. A Teoria do Crescimento Endógeno e o Desenvolvimento Endógeno Regional: investigação das convergências em um cenário pós-cepalino. Revista Econômica do Nordeste, Fortaleza, v. 32, n. Especial, p. 467-482, novembro de 2001. Disponível em: < http://www.bnb.gov.br/content/aplicacao/ETENE/Anais/docs/ren2001_v32_ne_a2.pd f>. Acessado em: 15 ago. 2014.

SILVA, Jorge Antonio Santos. Turismo, Crescimento e Desenvolvimento: uma análise urbano-regional baseada em cluster. Tese (Doutorado) - Escola de Comunicações e Artes/Universidade de São Paulo - USP, São Paulo, defendida em 
23 de junho de 2004, 480 f. v.1 e v.2. Disponível em:

$<$ www.teses.usp.br/teses/disponiveis/27/27148/tde.../JorgeAntonio.pdf $>$. Acessado em: 09 ago. 2014.

SOUZA, Nali de Jesus de. Desenvolvimento Regional. São Paulo: Atlas, 2009.

TEIXEIRA, Érika Resende; SILVA, Roseli da. Educação e crescimento econômico: uma análise econométrica para os municípios de São Paulo (1980-2000). Revista Jovens Pesquisadores, vol. 3, $\mathrm{n}^{\circ} 1$ (4), jan.-jun., 2006. Disponível em: <http://mackenzie.br/fileadmin/Graduacao/CCSA/Publicacoes/Jovens_Pesquisadores 104/3.4.08.pdf>. Acessado em: 05 ago. 2014.

TYSZLER, M. Econometria Espacial: discutindo medidas para a matriz de ponderação espacial. Fundação Getúlio Vargas, 2006.

Mário Sérgio Pedroza Lobão. Doutorando em Desenvolvimento Regional e Agronegócio (PGDRA/UNIOESTE); Instituto Federal do Acre (IFAC); Professor de Economia; Rua Guanabara - 640, Jardim Santa Maria - Toledo/PR. mario.lobao@ifac.edu.br

Rubicleis Gomes da Silva. Doutor em Economia Aplicada (UFV); Universidade Federal do Acre (UFAC); Professor de Métodos Quantitativos aplicado à Economia; Campus Universitário - BR 364, Km 4 - Distrito Industrial - Rio Branco/AC.rubicleis@uol.com.br 